\title{
Training in Endoscopy: Colonoscopy
}

\author{
Hyun Joo Jang \\ Division of Gastroenterology and Hepatology, Department of Internal Medicine, Hallym University School of Medicine, Hwaseong, Korea
}

Colonoscopy is effective in reducing the morbidity and mortality associated with colorectal cancer (CRC). Interval cancers or postcolonoscopy CRCs, are cancers detected within the surveillance interval, or between 6-36 months after a clearing colonoscopy. The incidence of interval cancers is 3.4\%-9.2\% of all detected CRCs, as reported in population-based studies. Colonoscopy is a technically difficult procedure that is challenging to learn, and needs time and effort to gain competency. Therefore, trainee competence is a critical component of CRC screening and surveillance. Herein, we review the colonoscopy training methods and quality assessment metrics for colonoscopy competency. Clin Endosc 2017;50:322-327

Key Words: Colonoscopy; Education

\section{INTRODUCTION}

Colonoscopy is a widely performed procedure in patients with abdominal symptoms, and is an integral part of all colorectal cancer (CRC) screening programs. Colonoscopy detects and prevents $\mathrm{CRC},{ }^{1-3}$ and is valuable in the diagnosis and treatment of non-neoplastic conditions. Interval cancers, or post-colonoscopy CRCs, are cancers detected within the surveillance interval, or between 6-36 months after a clearing colonoscopy. The incidence of interval cancers is $3.4 \%-9.2 \%$ of all detected CRCs, as reported in population-based studies. ${ }^{46}$ Colonoscopy can lead to rare but serious complications ${ }^{3,7}$ and poorly performed colonoscopies are associated with higher rates of interval cancers. ${ }^{4}$

The discipline of colonoscopy has advanced significantly over the years, and a variety of training methods have been developed to enhance the training of beginners. Colonoscopy

Received: May 15, 2017 Revised: July 15, 2017

Accepted: July 21, 2017

Correspondence: Hyun Joo Jang

Division of Gastroenterology and Hepatology, Department of Internal Medicine, Hallym University School of Medicine, 7 Keunjaebong-gil, Hwaseong 18450, Korea

Tel: +82-31-8086-2450, Fax: +82-31-8086-2029, E-mail: jhj1229@hallym.or.kr

(c) This is an Open Access article distributed under the terms of the Creative Commons Attribution Non-Commercial License (http://creativecommons.org/ licenses/by-nc/3.0) which permits unrestricted non-commercial use, distribution, and reproduction in any medium, provided the original work is properly cited. is a technically challenging procedure, which needs training and experience, to be able to perform a safe and high-quality colonoscopy. Competency in the basic skills for various endoscopic procedures is an important part of gastroenterology fellowship training programs. The colonoscopy procedure must be of the highest possible quality, and measures of quality should be maintained. In this paper, we review the colonoscopy training methods for a successful cecal intubation and withdrawal, as well as the quality assessment metrics for colonoscopy competency.

\section{TECHNIQUES FACILITATING THE INSERTION OF THE COLONOSCOPY}

\section{Simulation models}

Various simulation models, including physical and virtual models, have been used worldwide, for colonoscope insertion training. There are two available physical models: the Colonoscope training model (Kyoto Kagaku Co., Ltd., Kyoto, Japan) and Colonoscopy Simulator Type II (Koken Co., Ltd., Tokyo, Japan). Korean Society of Gastrointestinal Endoscopy (KSGE) provides regular training programs with hands-on colonoscopy courses, using physical models. The Colonoscope training model provides a wide range of colon case models from simple to difficult cases, with several variations of loop 
formations. The Colonoscopy Simulator Type II training model allows the practice of colonoscope insertion and provides training in endoscopic interventions, such as hemostasis and the resection of polyps, and insertion into the small bowel using balloon enteroscopy.

In addition, several computer-simulated endoscope programs exist: the Simbionix Simulator GI Mentor (Simbionix USA Corporation, Cleveland, OH, USA), Olympus Colonoscopy Simulator Endo TS-1 (Olympus KeyMed, Southend-on-Sea, UK), AccuTouch Endoscopy Simulator CAE Healthcare (Canada), and LM-107 Simulator Type II (Koken Co., Ltd., Tokyo, Japan). All these simulators appear to be valuable for basic training in colonoscopy. In a prospective randomized trial, a simulator-based training group, which received 3 hours of training on the simulator, achieved better patient comfort on flexible sigmoidoscopy, compared to that achieved by the patient-based training group. ${ }^{8}$ Early data on the Olympus Endo TS-1 also indicated that simulators are a valuable tool for learning colonoscopy. Specifically, a simulator-based training group, which received 16 hours of training with three simulated cases, demonstrated a significantly enhanced performance on simulated cases, compared to a patient-based training group, which spent an equal amount of time with bedside teaching. ${ }^{9}$ The Simulator-based training group had shorter completion times, higher completion rates, and demonstrated higher technical skill (reduced pain scores, improved loop management, and more meticulous use of abdominal pressure) compared to the patient-based training group. Thus, training on simulators accelerates the initial phase of the colonoscopy learning curve, with reduced patient discomfort, following live colonoscopy. The potential impact of simulators on therapeutic procedures remains to be evaluated.

\section{Magnetic navigation devices}

Magnetic navigation devices enable endoscopists to view the three-dimensional endoscopic configuration and the precise location of the endoscope in the abdomen. Magnetic navigation devices have been reported to have significantly improved colonoscopy performance of trainees, as well as experts, in technically challenging cases. ${ }^{10}$ Magnetic navigation devices help loops to be straightened or controlled effectively, reducing intubation time, and improving completion rates. In addition, the the pressure of the hand on the abdomen more accurate and effective, as the endoscopist and the assistant can visualize the magnetic image views. A recent meta-analysis reported that adjuvant magnetic endoscopic imaging is associated with a lower risk of colonoscopy failure and shorter cecal intubation time, compared to conventional colonoscopy. ${ }^{11}$

\section{Double-balloon colonoscopy}

In clinical colonoscopy, the X-ray can act as a guide for less experienced endoscopists. However, routine use of X-ray for colonoscopy training carries a risk of radiation exposure for the patients. Balloon-assisted enteroscopy for the anal route might provide a good teaching model for colonoscopy using $\mathrm{X}$-ray images, if it is available in the hospital. As assistants or observers of enteroscopic procedures, trainees are able to observe looping shapes and right/left turn shortening on the X-ray images. Double-balloon colonoscopy (DBC) is known to be useful for cecal intubation, after an initial incomplete colonoscopy due to various reasons. ${ }^{12} \mathrm{~A}$ recent randomized, controlled, crossover study compared the cecal intubation rate (CIR) and learning curve for DBC in endoscopy-naïve medical students using a physical colonic simulator, versus those performing conventional colonoscopy. The DBC group had a higher CIR compared to the conventional colonoscopy group ( $73 \%$ vs. $7 \%, p<0.001) .{ }^{13}$ Thus, DBC could be a valuable teaching option for cecal intubation, shortening the training period, and possibly reducing the need for colonoscopy training.

\section{Auxiliary techniques}

It is important for endoscopists to minimize loop formation using basic colonoscopic techniques (such as torque, pushing forward and pulling back, hooking the fold, jiggling, right/left turn shortening, and suctioning excess air) to achieve a successful cecal intubation with minimal abdominal pain. Several auxiliary methods can assist with cecal intubation.

\section{Water immersion colonoscopy}

Overinflation of the colon using air insufflation renders the colon long and tortuous (because the colon is a mobile and easily distensible organ), making it difficult to advance the colonoscope effectively. Therefore, endoscopists attempt to reduce air insufflation, frequently sucking air during colonoscope insertion. Water infusion instead of air insufflation, is a useful tip to avoid over-distension of the intestine with air. Similarly, performing an intestinal angulation widening during the colonoscope insertion process is also helpful. A randomized controlled trial reported a reduced insertion time to the splenic flexure with an injection of $200 \mathrm{~mL}$ of water at the rectosigmoid junction. ${ }^{14}$ The weight of the water in the left colon reduces the sigmoid colon angulation and loop formation. Although a recent meta-analysis comparing water infusion versus air insufflation during the colonoscope insertion, reported that water infusion does not improve the CIR compared to that for air insufflation, the adenoma detection rate (ADR) was slightly higher, and procedure-related abdominal pain was reduced by the water infusion technique. ${ }^{15}$ 


\section{Changing the position of the patient}

Colonoscopy is usually initiated, positioning the patient in the left lateral decubitus position. When the endoscopist encounters difficulty during colonoscope insertion, changing the position of the patient might be of help to advance the endoscope. The splenic flexure has a sharp angulation in the left lateral decubitus position. Positioning the patient in right lateral decubitus or supine position, can allow an easier passage from the angulated splenic flexure up to the mid-transverse colon. The left lateral position is suitable for intubating the endoscope from the mid-transverse colon to the distal ascending colon, while the left lateral or supine position is helpful for advancing the endoscope from the distal ascending colon to the cecum. Sometimes, the supine or right lateral position can help the endoscope in passing the sigmoido-descending junction. Changing the position of the patient might also slightly increase the ADR. ${ }^{16-18}$ However, this is debatable, as the results seem to be controversial, with one recent trial indicating no significant improvement. ${ }^{19}$ Other studies have suggested that there is an improvement in the ADR distal to the hepatic flexure, ${ }^{20}$ and that the examination of the right colon in the left lateral position significantly increases the ADR in the right colon. $^{21}$

\section{Abdominal compression}

During abdominal compression, an assistant presses the relevant part of the abdomen, where a loop is expected, with one or both hands. The colonoscope should be straightened before abdominal compression to enhance the compression effect. Although abdominal compression can be performed on any part of the abdomen where a loop is expected, the common compression sites are the sigmoid colon, sigmoid-descending junction, and transverse colon.

\section{LEARNING CURVE FOR COLONOSCOPY}

CIR is the most frequently used indicator for assessing competency in colonoscopy. The consequences of an incomplete colonoscopy include missed diagnoses and the failure to prevent interval cancers. A photographic recording of the cecal intubation should be obtained, with images of the cecum or terminal ileum. Cecal intubation is defined as insertion of the colonoscope, to a point proximal to the ileocecal valve, with the entire cecum inspected. ${ }^{22}$ The American Society for Gastrointestinal Endoscopy (ASGE) suggests that the CIR of competent colonoscopists should be greater than $95 \%$ for cases involving the screening of healthy adults and greater than $90 \%$ for all cases. ${ }^{23}$ In addition, a study in the United Kingdom reported an unadjusted CIR of $92.5 \%$ for competent colonoscopists (95\% confidence interval, $91.2 \%$ to $92.6 \%)^{24}$ Furthermore, the English Bowel Cancer Screening Program reported an unadjusted CIR of 95.2\% (range, 76.2\%-100\%) in the first 3 years of screening. ${ }^{25}$ Thus, an unadjusted CIR of $90 \%$ is considered the minimal standard, and colonoscopists should achieve an unadjusted CIR of at least $95 \%$.

A recent systematic review on assessing competency in colonoscopy investigated 10 studies that used the independent CIR, 6 studies that used the independent CIR and cecal intubation time, one study that used the independent CIR and total procedure time, and 2 studies that used a comprehensive competency assessment. ${ }^{26}$ Eleven of the 19 studies using the $>90 \%$ independent CIR as the assessment criteria with/without the time limit, also achieved competency in accordance with the minimal competency criteria of the core Mayo Colonoscopy Skills Assessment Tool. Four of the 10 studies using the independent CIR without the time limit as the assessment criteria, concluded that trainees need to perform approximately 280-300 colonoscopies to achieve a CIR of $>90 \%$. One study assessed total colonoscopy including multiple aspects of the procedure (independent CIR, polypectomy, and hemostasis), and reported that trainees need to perform 467 colonoscopies to achieve more than $90 \%$ total colonoscopy competency. In addition, 275 colonoscopies were required to achieve the minimal competency criteria of the core Mayo Colonoscopy Skills Assessment Tool.

\section{PREREQUISITES FOR HIGH-LEVEL WITHDRAWAL}

\section{Bowel preparation}

A good bowel preparation is one of the most important factors in achieving a high-quality colonoscopy. Suboptimal bowel preparation has been associated with incomplete colonoscopy, prolonged colonoscopy time, and reduced diagnostic yield. $^{27-29}$ A recent meta-analysis reported that a split-dose polyethylene glycol (PEG) regimen enhances the quality of bowel preparation, improves patient compliance, and decreases the frequency of nausea or vomiting, compared to a fulldose PEG regimen. ${ }^{30}$

The time interval between the end of PEG intake and the initiation of colonoscopy can affect the quality of bowel preparation. ${ }^{31}$ Patients with a shorter time interval between bowel preparation and initiation of colonoscopy show better bowel preparation. ${ }^{31}$ Specifically, the quality of bowel preparation is better when the colonoscopy is performed within 7 hours from the initiation of PEG intake, and within 4 hours from the end of PEG intake. ${ }^{31}$ If a patient is scheduled for a colonoscopy in the afternoon, bowel preparation can be per- 
formed on the same day, leading to better effectiveness, feasibility, and safety, as well as fewer side effects and improved patient compliance. $^{31,32}$

A number of different scoring systems for bowel preparation are commonly used, making comparisons difficult. Validated bowel preparation scales include the following: the Aronchick bowel preparation scale ${ }^{33}$ Boston bowel preparation scale (BBPS), ${ }^{34}$ and Ottawa bowel preparation scale. ${ }^{35}$ All involve relatively complex scoring systems. However, it is recommended that endoscopists record the bowel preparation quality for every colonoscopy. A systematic review of these validated scales reported that the BBPS was the best and should be used in clinical settings. The BBPS separately assesses the segments of colon (right, transverse, and left colon), after each segment has been washed and thoroughly suctioned. BBPS scores are significantly associated with polyp detection rate and insertion/withdrawal time (WT). In addition, recommended follow-up intervals for surveillance colonoscopy exist according to the BBPS score..$^{36} \mathrm{~A}$ total score of less than 2 indicates that repeat colonoscopy within a year should be recommended. The BBPS offers an online training program (BBPS educational program, www.cori.org/bbps).

\section{Withdrawal time}

Endoscopists observe most of the colonic mucosa during the withdrawal of the colonoscope from the cecum to the rectum, and there is a significant association between the ADR and the colonoscopy WT, which is the length of time taken to withdraw the colonoscope after the cecum or terminal ileum has been reached.

Initial studies reported that a WT $>6$ min was associated with a higher ADR. ${ }^{37}$ Similarly, retrospective studies reported an association between longer WTs and higher ADRs. ${ }^{38,39}$ Most of the recent quality recommendations indicate that WT is a critical measure of the quality of mucosal inspection. ${ }^{23,40}$ The ASGE recommends that the WT should be routinely measured in all colonoscopy examinations, and mean WT should be more than 6 minutes, for negative screening procedures. ${ }^{23}$ The KSGE also recommends a mean WT of 6 minutes or longer for a colonoscopy. ${ }^{41,42}$ Trainees or endoscopists with an ADR below the recommended thresholds should extend their mean WT to more than 6 minutes.

\section{Adenoma detection rate}

ADR refers to the proportion of colonoscopies in which one or more adenomas are detected. The ADR is considered to be the most reliable indicator for the risk of interval cancer and is widely used as a marker of colonoscopy quality. ${ }^{43}$ The Polish Bowel Cancer Screening Program and a US study showed that a lower ADR is associated with higher rates of post colonos- copy CRC. ${ }^{4}$ The earlier recommendation was that individual colonoscopists should detect one or more adenomas in at least $25 \%$ of men and $15 \%$ of women aged over 50 years, who undergo screening colonoscopy. ${ }^{37,44,45}$ However, recent ASGE recommendations suggest an overall ADR of more than 25\% (for men $\geq 30 \%$, for women $\geq 20 \%$ ). ${ }^{23}$ In the United Kingdom, minimal ADR of $15 \%$ is recommended, with an aspirational ADR target of $20 \%{ }^{40}$

The ADR varies according to the nature of the population undergoing colonoscopy and the indication for the procedure. The ADR varies between observers, centers, patient cohorts, and even within procedures in the same person. A systematic review investigated 6 studies in which patients underwent tandem colonoscopies; the overall miss rates for all polyps and adenomas were $21 \%$ and $22 \%$, respectively. ${ }^{46} \mathrm{ADR}$ is associated with several procedural factors, including quality of bowel preparation, WT, and changes in the position of the patient. ${ }^{6}$ Lower ADRs are associated with higher rates of interval cancers. ${ }^{4,6}$ Colonoscopists with an ADR $<20 \%$ have a ten times higher hazard ratio for interval cancer, compared to that for colonoscopists with an ADR $>20 \% .{ }^{4}$ Furthermore, withdrawal technique explains a significant portion of the differences in ADR between endoscopists. ${ }^{39}$ Several studies have investigated whether various interventions for colonoscopy quality improvement affect the ADR or polyp detection rate, and two studies have shown educational interventions to be successful. One of these studies reported that a group who underwent Endoscopic Quality Improvement Program training increased their ADR to $47 \%$, while the ADR for control group remained unchanged at $35 \% .{ }^{47}$ Thus, a simple educational training program can improve the ADR. Another study reported that endoscopists with a WT of at least 8 minutes, guided by an intermittent audible signal every 2 minutes, had higher detection rates for any type of neoplasia compared to endoscopists without the audible guide. ${ }^{48}$ However, a recent systematic review reported that interventions targeting endoscopist performance are ineffective in improving the ADR or polyp detection rate. ${ }^{49}$ An additional study reported that the ADR among gastroenterology fellows varies between 14\%-36\% during colonoscopy training, and indicated that feedback should be provided early during the fellowship training. ${ }^{50}$

\section{CONCLUSIONS}

The prevalence of lower gastrointestinal diseases including colorectal polyps, inflammatory bowel diseases, and CRC is increasing in South Korea, due to changing lifestyles and westernized diet. ${ }^{51,52}$ Thus, the demand for colonoscopy as a screening modality as well as a diagnostic and interventional 
tool has increased. Colonoscopists should have the technical expertise and experience to minimize adverse events and maximize the benefits of detecting and removing neoplastic lesions. Effective and comprehensive training is an essential factor for high-quality colonoscopy. Trainees should learn basic colonoscopy skills and gain an experience of various types of colonoscopic cases. In addition, trainees should document their key quality indicators to guide them in further improvement. Virtual endoscopy simulators and physical simulation models are useful in the early phase of training. The main disadvantage of the discussed virtual simulators, physical models, and magnetic navigation devices, is that they are rarely available in most of the training hospitals in Korea due to their high price. In addition, the development of systematic training program for colonoscopy is necessary in the near future.

\section{Conflicts of Interest}

The author has no financial conflicts of interest.

\section{REFERENCES}

1. Jacob BJ, Moineddin R, Sutradhar R, Baxter NN, Urbach DR. Effect of colonoscopy on colorectal cancer incidence and mortality: an instrumental variable analysis. Gastrointest Endosc 2012;76:355-364.e1.

2. Kahi CJ, Imperiale TF, Juliar BE, Rex DK. Effect of screening colonoscopy on colorectal cancer incidence and mortality. Clin Gastroenterol Hepatol 2009;7:770-775; quiz 711.

3. Nishihara R, Wu K, Lochhead P, et al. Long-term colorectal-cancer incidence and mortality after lower endoscopy. N Engl J Med 2013;369:1095-1105.

4. Kaminski MF, Regula J, Kraszewska E, et al. Quality indicators for colonoscopy and the risk of interval cancer. N Engl J Med 2010;362:17951803.

5. Bressler B, Paszat LF, Chen Z, Rothwell DM, Vinden C, Rabeneck L. Rates of new or missed colorectal cancers after colonoscopy and their risk factors: a population-based analysis. Gastroenterology 2007;132:96102.

6. Corley DA, Jensen CD, Marks AR, et al. Adenoma detection rate and risk of colorectal cancer and death. N Engl J Med 2014;370:1298-1306.

7. Korman LY, Overholt BF, Box T, Winker CK. Perforation during colonoscopy in endoscopic ambulatory surgical centers. Gastrointest Endosc 2003;58:554-557.

8. Sedlack RE, Kolars JC, Alexander JA. Computer simulation training enhances patient comfort during endoscopy. Clin Gastroenterol Hepatol 2004;2:348-352.

9. Haycock A, Koch AD, Familiari P, et al. Training and transfer of colonoscopy skills: a multinational, randomized, blinded, controlled trial of simulator versus bedside training. Gastrointest Endosc 2010;71:298-307.

10. Shah SG, Brooker JC, Thapar C, Suzuki N, Williams CB, Saunders BP. Effect of magnetic endoscope imaging on patient tolerance and sedation requirements during colonoscopy: a randomized controlled trial. Gastrointest Endosc 2002;55:832-837.

11. Mark-Christensen A, Brandsborg S, Iversen LH. Magnetic endoscopic imaging as an adjuvant to elective colonoscopy: a systematic review and meta-analysis of randomized controlled trials. Endoscopy 2015;47:251261.

12. Hotta K, Katsuki S, Ohata K, et al. A multicenter, prospective trial of to- tal colonoscopy using a short double-balloon endoscope in patients with previous incomplete colonoscopy. Gastrointest Endosc 2012;75:813-818.

13. Sunada K, Shinozaki S, Yano T, et al. Double-balloon colonoscopy has a higher cecal intubation rate than conventional colonoscopy using a colon simulator. Dig Dis Sci 2017;62:979-983.

14. Baumann UA. Water intubation of the sigmoid colon: water instillation speeds up left-sided colonoscopy. Endoscopy 1999;31:314-317.

15. Hafner S, Zolk K, Radaelli F, Otte J, Rabenstein T, Zolk O. Water infusion versus air insufflation for colonoscopy. Cochrane Database Syst Rev 2015;(5):CD009863.

16. East JE, Suzuki N, Arebi N, Bassett P, Saunders BP. Position changes improve visibility during colonoscope withdrawal: a randomized, blinded, crossover trial. Gastrointest Endosc 2007;65:263-269.

17. Ghosh S, Iacucci M. Dynamic position change at colonoscopy improves adenoma detection. Can J Gastroenterol 2013;27:508.

18. Lucendo AJ. Colonoscopy in obese patients: time to change position. Dig Dis Sci 2013;58:608-609.

19. Ou G, Kim E, Lakzadeh P, et al. A randomized controlled trial assessing the effect of prescribed patient position changes during colonoscope withdrawal on adenoma detection. Gastrointest Endosc 2014;80:277283.

20. Köksal AŞ, Kalkan IH, Torun S, et al. A simple method to improve adenoma detection rate during colonoscopy: altering patient position. Can J Gastroenterol 2013;27:509-512.

21. Ball AJ, Johal SS, Riley SA. Position change during colonoscope withdrawal increases polyp and adenoma detection in the right but not in the left side of the colon: results of a randomized controlled trial. Gastrointest Endosc 2015;82:488-494.

22. Rex DK, Schoenfeld PS, Cohen J, et al. Quality indicators for colonoscopy. Am J Gastroenterol 2015;110:72-90.

23. Rex DK, Schoenfeld PS, Cohen J, et al. Quality indicators for colonoscopy. Gastrointest Endosc 2015;81:31-53.

24. Rajasekhar PT, Rutter MD, Bramble MG, et al. Achieving high quality colonoscopy: using graphical representation to measure performance and reset standards. Colorectal Dis 2012;14:1538-1545.

25. Lee TJ, Rutter MD, Blanks RG, et al. Colonoscopy quality measures: experience from the NHS Bowel Cancer Screening Programme. Gut 2012;61:1050-1057.

26. Shahidi N, Ou G, Telford J, Enns R. Establishing the learning curve for achieving competency in performing colonoscopy: a systematic review. Gastrointest Endosc 2014;80:410-416.

27. Hendry PO, Jenkins JT, Diament RH. The impact of poor bowel preparation on colonoscopy: a prospective single centre study of 10,571 colonoscopies. Colorectal Dis 2007;9:745-748.

28. Bernstein CN, Greenberg H, Boult I, Chubey S, Leblanc C, Ryner L. A prospective comparison study of MRI versus small bowel follow-through in recurrent Crohn's disease. Am J Gastroenterol 2005;100:2493-2502.

29. Jang JY, Chun HJ. Bowel preparations as quality indicators for colonoscopy. World J Gastroenterol 2014;20:2746-2750.

30. Kilgore TW, Abdinoor AA, Szary NM, et al. Bowel preparation with split-dose polyethylene glycol before colonoscopy: a meta-analysis of randomized controlled trials. Gastrointest Endosc 2011;73:1240-1245.

31. Eun CS, Han DS, Hyun YS, et al. The timing of bowel preparation is more important than the timing of colonoscopy in determining the quality of bowel cleansing. Dig Dis Sci 2011;56:539-544.

32. Hong SN, Sung IK, Kim JH, et al. The effect of the bowel preparation status on the risk of missing polyp and adenoma during screening colonoscopy: a tandem colonoscopic study. Clin Endosc 2012;45:404-411.

33. Aronchick CA. Bowel preparation scale. Gastrointest Endosc 2004;60:1037-1038; author reply 1038-1039.

34. Calderwood AH, Jacobson BC. Comprehensive validation of the Boston bowel preparation scale. Gastrointest Endosc 2010;72:686-692.

35. Rostom A, Jolicoeur E. Validation of a new scale for the assessment of bowel preparation quality. Gastrointest Endosc 2004;59:482-486. 
36. Kahi CJ, Vemulapalli KC, Johnson CS, Rex DK. Improving measurement of the adenoma detection rate and adenoma per colonoscopy quality metric: the Indiana University experience. Gastrointest Endosc 2014;79:448-454.

37. Overholt BF, Brooks-Belli L, Grace M, et al. Withdrawal times and associated factors in colonoscopy: a quality assurance multicenter assessment. J Clin Gastroenterol 2010;44:e80-e86.

38. Rex DK. Colonoscopic withdrawal technique is associated with adenoma miss rates. Gastrointest Endosc 2000;51:33-36.

39. Lee RH, Tang RS, Muthusamy VR, et al. Quality of colonoscopy withdrawal technique and variability in adenoma detection rates (with videos). Gastrointest Endosc 2011;74:128-134.

40. Rees CJ, Thomas Gibson S, Rutter MD, et al. UK key performance indicators and quality assurance standards for colonoscopy. Gut 2016;65:1923-1929.

41. Lee BI, Hong SP, Kim SE, et al. Korean guidelines for colorectal cancer screening and polyp detection. Clin Endosc 2012;45:25-43.

42. Lee BI, Hong SP, Kim SE, et al. [Korean guidelines for colorectal cancer screening and polyp detection]. Korean J Gastroenterol 2012;59:65-84.

43. Millan MS, Gross P, Manilich E, Church JM. Adenoma detection rate: the real indicator of quality in colonoscopy. Dis Colon Rectum 2008;51:1217-1220.

44. Rex DK, Petrini JL, Baron TH, et al. Quality indicators for colonoscopy. Gastrointest Endosc 2006;63(4 Suppl):S16-S28.

45. Rex DK, Bond JH, Winawer S, et al. Quality in the technical perfor- mance of colonoscopy and the continuous quality improvement process for colonoscopy: recommendations of the U.S. Multi-Society Task Force on Colorectal Cancer. Am J Gastroenterol 2002;97:1296-1308.

46. van Rijn JC, Reitsma JB, Stoker J, Bossuyt PM, van Deventer SJ, Dekker E. Polyp miss rate determined by tandem colonoscopy: a systematic review. Am J Gastroenterol 2006;101:343-350.

47. Coe SG, Crook JE, Diehl NN, Wallace MB. An endoscopic quality improvement program improves detection of colorectal adenomas. Am J Gastroenterol 2013;108:219-226; quiz 227.

48. Barclay RL, Vicari JJ, Greenlaw RL. Effect of a time-dependent colonoscopic withdrawal protocol on adenoma detection during screening colonoscopy. Clin Gastroenterol Hepatol 2008;6:1091-1098.

49. Corley DA, Jensen CD, Marks AR. Can we improve adenoma detection rates? A systematic review of intervention studies. Gastrointest Endosc 2011;74:656-665.

50. van Doorn SC, Klanderman RB, Hazewinkel Y, Fockens P, Dekker E. Adenoma detection rate varies greatly during colonoscopy training. Gastrointest Endosc 2015;82:122-129.

51. Nelson DB, McQuaid KR, Bond JH, Lieberman DA, Weiss DG, Johnston TK. Procedural success and complications of large-scale screening colonoscopy. Gastrointest Endosc 2002;55:307-314.

52. Rutter MD, Nickerson C, Rees CJ, Patnick J, Blanks RG. Risk factors for adverse events related to polypectomy in the English Bowel Cancer Screening Programme. Endoscopy 2014;46:90-97. 